\title{
Evaluation of lead and cadmium concentrations in lipstick and eye pencil cosmetics
}

\author{
Rozhan Feizi $^{1 \oplus}$, Nematollah Jaafarzadeh ${ }^{2^{\circledR}}$, Hamideh Akbari $^{3^{\circledR}}$, Sahand Jorfi $^{2^{*}(}$ \\ ${ }^{1}$ Student Research Committee, Ahvaz Jundishapur University of Medical Sciences, Ahvaz, Iran \\ ${ }^{2}$ Environmental Technologies Research Center, Ahvaz Jundishapur University of Medical Sciences, Ahvaz, Iran \\ ${ }^{3}$ Department of Environmental Health, Health Promotion Research Center and School of Public Health, Zahedan University of Medical \\ Sciences, Zahedan, Iran
}

\begin{abstract}
Background: The aim of this study was to determine the concentrations of lead $(\mathrm{Pb})$ and cadmium $(\mathrm{Cd})$ in lipstick and eye pencil cosmetics of different grades in the markets of Iran.

Methods: This descriptive study was conducted in Ahvaz city in 2018. Sixty different samples of lipstick and eye pencil of three common brands were selected and analyzed using the Inductively Coupled Plasma Atomic Emission Spectroscopy (ICP-OES) and the results were compared with standard values recommended by the Food and Drug Administration (FDA). The analysis of lipsticks was based on producer country and colors and producer country only for eye pencil.

Results: The mean concentrations of $\mathrm{Pb}$ and $\mathrm{Cd}$ were 41.86 and $53.42 \mu \mathrm{g} / \mathrm{g}$, respectively. Concentrations of lead were higher than those of Cd in lipsticks, while for eye pencil, Cd showed higher concentrations. The overall results indicated that in all brands and colors of lipsticks, only $33 \%$ of the samples had $\mathrm{Pb}$ content less than the FDA limit, and among lipstick samples, 44\% had Cd concentration less than the FDA limit of $3 \mu \mathrm{g} / \mathrm{g}$, however, in $100 \%$ of the eye pencil samples, the concentration of $\mathrm{Cd}$ was higher than the recommended value of $3 \mu \mathrm{g} / \mathrm{g}$.

Conclusion: Given the health risks of exposure to heavy metals and in order to increase community awareness about the harmful effects of cosmetics, it is necessary to monitor the concentration of these toxic elements in these products and encourage the manufactures to meet the FDA standards.

Keywords: Lead, Cadmium, Cosmetics, Environmental pollution

Citation: Feizi R, Jaafarzadeh N, Akbari H, Jorfi S. Evaluation of lead and cadmium concentrations in lipstick and eye pencil cosmetics. Environmental Health Engineering and Management Journal 2019; 6(4): 277-282. doi: 10.15171/EHEM.2019.31.
\end{abstract}

\section{Article History:}

Received: 10 August 2019

Accepted: 2 November 2019

ePublished: 6 December 2019

\section{Introduction}

In recent years, the worldwide use of cosmetic products has had a big boost due to, their daily use for beauty, cleaning, improving or changing the skin $(1,2)$. Cosmetic products are applied directly to human skin, and because of their components, their use can present risks to human health, causing possible reactions, such as hypersensitivity and irritant reactions $(3,4)$. Recently, the occurrence of heavy metals pollution in cosmetics has attracted worldwide attention. Lead $(\mathrm{Pb})$ and cadmium $(\mathrm{Cd})$ are two potentially harmful heavy metals that cause considerable concerns $(5,6) . \mathrm{Pb}$ contamination in cosmetics can originate from $\mathrm{Pb}$ solder, lead-based dyes in production material or from contaminated dust. $\mathrm{Pb}$ contributes to the preservation of paraffin and cosmetics on the skin. In rosin, the $\mathrm{Pb}$-tin is used to stabilize the color and also to produce red color (7). Exposure to $\mathrm{Pb}$ could accumulate in the body organs due to their long half-life, then, it would be absorbed by the red blood cells and circulated through the body. Symptoms may include abdominal pain, constipation, headaches, irritability, memory problems, inability to have children, and tingling in the hands and feet. In severe cases, anemia, seizures, coma, or death may occur (8-10). Cd is used in many cosmetic products according to its color properties as a colored pigment (11). Cd can accumulate in various organs and tissues, but mostly in kidney cortex. $\mathrm{Cd}$ exposure has been inconsistently associated with blood pressure. The symptoms of severe Cd ingestion are nausea, vomiting, abdominal cramps and pain, diarrhea, and tenseness (12-14). Cd also causes bone degradation because it affects calcium metabolism (15). Among cosmetic products, lipstick is one of the most commonly used one, which are produced from a range of chemicals and presented in a wide variety of dye. They are produced 
by adding pigments that may contain heavy metals as impurities in the pigment formulation (16-18). Moreover, lipsticks, because of their direct oral ingestion have the higher risk, which can irritate the negative effects of their chemicals. Studies on the use of lipstick among women show that a woman inadvertently ingests $1.8 \mathrm{~kg}$ of lipstick during her life $(19,20)$. Eye cosmetics could be another source of heavy metals exposure. Some cosmetics contain chemicals that can cause eye damage or heavy metals that can cause long-term health problems, such as $\mathrm{Pb}$ poisoning. Previous studies reported that various types of heavy metals, such as $\mathrm{Pb}$, mercury, $\mathrm{Cd}$, arsenic, nickel, and aluminium are detected in cosmetics, which pose health risks to consumers. Chronic exposure to these elements is associated with a variety of health problems, such as respiratory system cancer, skin disorders, Alzheimer, anemia, nervous system, reproductive disorders, cardiovascular problems, gastrointestinal disorders, impaired immunity, and even death (21-24). The world's largest producer of cosmetics products is divided into three categories: The European Union, the United States, and Japan. Iran has the seventh place in the world and is the third largest cosmetics importer and distributor in the Middle East $(7,25)$. Due to the fact that many of these cosmetics imported into the country through illegal entry, due to being fake, they cause physical complications and skin lesions and diseases, such as skin allergies, skin ulcers, and even cancer (26). In recent years, the worldwide use of cosmetic products has rapidly increased due to their daily use for beauty, cleaning, improving and changing the skin. Because of the adverse effects of health regarding the presence of heavy metals, it is necessary to monitor the level of these elements in cosmetic products. Hence, the main aim of this study was to determine the concentrations of $\mathrm{Pb}$ and $\mathrm{Cd}$ in eye pencil and lipstick marketed in Ahwaz, Iran.

\section{Materials and Methods \\ Materials}

All the chemicals used in the study were analytical grade. Cosmetic products including eye pencils and lipsticks of different brands and colors were randomly purchased from the local markets in Ahwaz, Iran. Nitric acid (65\%) and perchloric acid (70-72\%) were purchased from Sigma Aldrich. Plastic bottles and glass wares were washed with detergents, rinsed with deionized water, and dried at room temperature before use. All samples were filtered by $0.45 \mu \mathrm{m}$ filter paper. The concentrations of $\mathrm{Pb}$ and $\mathrm{Cd}$ were measured using Inductively Coupled Plasma Atomic Emission Spectroscopy (ICP-OES, GBC, ICP- Australia OES Integra XL). The ICP-OES device was operated under a plasma power of $1400 \mathrm{~W}$ and plasma gas flow rate of $14.5 \mathrm{~L} / \mathrm{min}$.

Sample collection

This descriptive study was conducted in Ahvaz city in
2018. Three different brands of lipsticks with most popular colors (red, pink, and brown) and eye pencil were randomly collected from the local market in Ahvaz city, Iran. Samples were produced by China, France, Turkey, Germany, and Korea. The samples were taken to the laboratory and kept at room temperature for the subsequent preparation and analysis. Samples characteristics are presented in Table 1. Sample size was selected according to Eq. (1): $\mathrm{n}=\left[\left(\mathrm{Z}^{2} \times \mathrm{S}^{2}\right) / \mathrm{d}^{2}\right](1)$

where, $z$ value for $95 \%$ confidence is $1.96, S$ is the standard deviation $=0.1$, and $d$ is the precision level $=0.05$ obtained from a study in Sari, Mazandaran (Iran) (27).

\section{$\mathrm{Pb}$ and $\mathrm{Cd}$ analysis}

The samples were dried at $80^{\circ} \mathrm{C}$ for 12 hours in an oven until constant weight was achieved. Afterwards, $1 \mathrm{~g}$ of dried samples was digested with $\mathrm{HNO}_{3}$, evaporated to near dryness on a hot plate, and then, cooled. The procedure was repeated with $\mathrm{HClO}_{4}$. More $\mathrm{HClO}_{4}$ were added until the evaporation of white fumes (marking the end of the digestion process) before heating to near dryness. The residual was diluted with deionized water, filtered through $0.45 \mu \mathrm{m}$ Whatman filter, and made-up to mark in $50 \mathrm{~cm}^{3}$ volumetric flasks, transferred to sample plastic bottles, and kept at room temperature for subsequent analysis (28). The concentrations of $\mathrm{Pb}$ and $\mathrm{Cd}$ were measured using the ICP-OES device.

\section{Statistical analysis}

Statistical analysis was done using SPSS version 16 (SPSS Inc., Chicago, IL, USA) at $P<0.05$. Descriptive statistical parameters, such as mean and standard error (SE) were used to describe the $\mathrm{Cd}$ and $\mathrm{Pb}$ concentrations in different cosmetic products. One-way analysis (ANOVA) was used to determine the significant difference between $\mathrm{Cd}$ and $\mathrm{Pb}$ concentrations in different types of cosmetics, brands, colors, and producer countries.

Table 1. Descriptive statistical analysis of quantitative monitoring of $\mathrm{Cd}$ and $\mathrm{Pb}$ in lipstick and eye pencil cosmetics products in Ahvaz, Iran

\begin{tabular}{|c|c|c|c|c|}
\hline Types of Cosmetics & Brand & Country & Color & Replicates \\
\hline \multirow{9}{*}{ Lipstick } & \multirow{3}{*}{1} & \multirow{3}{*}{ China } & Pink & 6 \\
\hline & & & Brown & 6 \\
\hline & & & Red & 6 \\
\hline & \multirow{3}{*}{2} & \multirow{3}{*}{ France } & Pink & 6 \\
\hline & & & Brown & 6 \\
\hline & & & Red & 6 \\
\hline & \multirow{3}{*}{3} & \multirow{3}{*}{ Turkey } & Pink & 6 \\
\hline & & & Brown & 6 \\
\hline & & & Red & 6 \\
\hline \multirow{3}{*}{ Eye pencil } & 1 & Germany & - & 6 \\
\hline & 2 & Korea & - & 6 \\
\hline & 3 & China & - & 6 \\
\hline Total sample & & & & 72 \\
\hline
\end{tabular}




\section{Results}

$\mathrm{Pb}$ and $\mathrm{Cd}$ concentrations

Descriptive statistics of the results for $\mathrm{Pb}$ and $\mathrm{Cd}$ concentrations in lipsticks and eye pencil based on the producer country, and cosmetics brands are presented in Table 2. The mean concentrations of $\mathrm{Pb}$ and $\mathrm{Cd}$ in all of the studied brands were 41.86 and $53.42 \mu \mathrm{g} / \mathrm{g}$, respectively.

\section{Quality according to producer country}

The $\mathrm{Pb}$ content obtained according to the producer country for lipsticks revealed that the highest $\mathrm{Pb}$ concentration was found in lipsticks produced in China (Figure 1a). Statistical analysis revealed no significant difference in the $\mathrm{Pb}$ concentration between Turkish and French products $(P<0.05)$, whereas, there was a significant difference in the mean $\mathrm{Pb}$ content between Chinese, Turkish, and French lipsticks $(P<0.001)$. Comparison of the $\mathrm{Pb}$ content in eye pencil according to the producer country revealed that the maximum and minimum $\mathrm{Pb}$ concentrations were observed in the products of China $(96.85 \mu \mathrm{g} / \mathrm{g})$ and Korea $(28.22 \mu \mathrm{g} / \mathrm{g})$, respectively. There was a significant difference in the average $\mathrm{Pb}$ content between German and Korean, and Chinese eye pencils (Figure 1b). Comparison of the Cd content in lipsticks according to the producer country revealed that the highest $\mathrm{Cd}$ concentration was found in the lipsticks produced in China and the lowest one was found in French brand (Figure 1c). According to the results of one-way ANOVA, there was a significant difference in the mean $\mathrm{Cd}$ content between producer countries $(P<0.001)$. Comparison of the Cd content in eye pencil according to the producer country revealed that the maximum and minimum $\mathrm{Pb}$ concentrations were observed in the products by China $(364.68 \mu \mathrm{g} / \mathrm{g})$ and Korea $(6.098 \mu \mathrm{g} / \mathrm{g})$, respectively (Figure 1d).

\section{Effect of color}

Comparison of the $\mathrm{Pb}$ content according to lipstick color revealed that the highest concentration of $\mathrm{Pb}$ was found
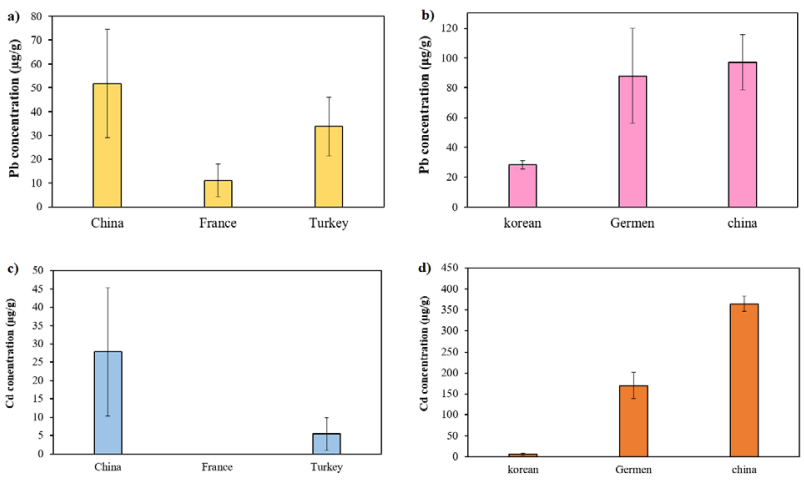

Figure 1. Comparison of the mean $\mathrm{Pb}$ level in lipsticks (a), eye pencil according to the producer country (b), Comparison of the mean Cd level in lipsticks (c), and eye pencil according to the producer country (d).

for red lipsticks and the lowest one was found for pink ones (Figure 2a). Statistical analysis revealed a significant difference between $\mathrm{Pb}$ concentration and color of lipstick samples $(P<0.001)$. Comparison of the $\mathrm{Cd}$ content according to lipstick color showed that the highest concentration of $\mathrm{Cd}$ was found in lipsticks produced by China in red color, while the lowest one was found in lipsticks produced by France in all colors and Turkey in pink color (Figure 2b).

\section{Comparison according to FDA}

According to the results reported by the Food and Drug Administration (FDA) on the $\mathrm{Pb}$ content in lipsticks in 2011, the limit value for $\mathrm{Pb}$ as a color additive in cosmetics is $20 \mu \mathrm{g} / \mathrm{g}(6,29)$. It was found that only $33 \%$ of all brands and colors of lipsticks had $\mathrm{Pb}$ content less than the FDA limit that was related to French brand. In contrast, all Turkish and Chinese products had $\mathrm{Pb}$ concentrations higher than the permitted limit (Figure 3a). As well, 44\% of all lipstick samples had Cd content less than the FDA limit of $3 \mu \mathrm{g} / \mathrm{g}$, that was related to French and Turkish lipsticks with pink color (Figure $3 \mathrm{~b}$ ). Moreover, $\mathrm{Pb}$ levels

Table 2. Descriptive statistical analysis of quantitative monitoring of $\mathrm{Cd}$ and $\mathrm{Pb}$ in lipstick and eye pencil cosmetics products in Ahvaz, Iran

\begin{tabular}{|c|c|c|c|c|c|}
\hline \multirow{2}{*}{ Types of Cosmetics } & \multirow{2}{*}{ Brand } & \multirow{2}{*}{ Country } & \multirow{2}{*}{ Color } & \multicolumn{2}{|c|}{ Mean \pm SE } \\
\hline & & & & $\mathrm{Pb}(\mu \mathrm{g} / \mathrm{g})$ & $\mathrm{Cd}(\mu \mathrm{g} / \mathrm{g})$ \\
\hline \multirow{9}{*}{ Lipstick } & \multirow{3}{*}{1} & \multirow{3}{*}{ China } & Red & $81.15 \pm 7.20$ & $51.11 \pm 1.67$ \\
\hline & & & Brown & $41.63 \pm 0.91$ & $16.23 \pm 1.13$ \\
\hline & & & Pink & $32.38 \pm 1.23$ & $16.27 \pm 1.19$ \\
\hline & \multirow{3}{*}{2} & \multirow{3}{*}{ France } & Red & $18.86 \pm 0.55$ & 0 \\
\hline & & & Brown & $11.19 \pm 0.51$ & 0 \\
\hline & & & Pink & $2.91 \pm 0.05$ & 0 \\
\hline & \multirow{3}{*}{3} & \multirow{3}{*}{ Turkey } & Red & $49.05 \pm 0.45$ & $6.07 \pm 0.52$ \\
\hline & & & Brown & $31.09 \pm 0.52$ & $10.26 \pm 0.48$ \\
\hline & & & Pink & $21.10 \pm 0.52$ & 0 \\
\hline \multirow{3}{*}{ Eye pencil } & 1 & China & - & $96.85 \pm 18.57$ & $364.68 \pm 47.96$ \\
\hline & 2 & Germen & - & $87.96 \pm 31.97$ & $170.41 \pm 14.70$ \\
\hline & 3 & Korea & - & $28.22 \pm 2.84$ & $6.09 \pm 0.92$ \\
\hline
\end{tabular}

SE: standard error, $\mathrm{Pb}$ : lead, $\mathrm{Cd}$ : cadmium. 

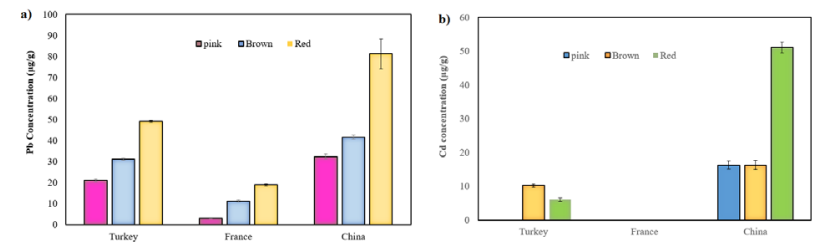

Figure 2. (a) Comparison of the $\mathrm{Pb}$ content according to lipstick color and (b) Comparison of the Cd content according to lipstick color.

in eye pencil was above the permitted limit in all samples tested (Figure 3c). However, $100 \%$ of eye pencil samples had Cd content above the recommended value of $3 \mu \mathrm{g} / \mathrm{g}$. In this study, the concentrations of $\mathrm{Pb}$ and $\mathrm{Cd}$ in the most cosmetics were higher than the recommended value by the FDA.

\section{Discussion}

In this study, samples were randomly collected from three different brands of lipsticks with most popular colors (red, pink, and brown) and eye pencil from the local market in Ahvaz, Iran. Samples were produced by China, France, Turkey, Germany, and Korea. The concentrations of $\mathrm{Pb}$ and $\mathrm{Cd}$ were measured in the cosmetic products. According to the results, the concentrations of $\mathrm{Pb}$ and Cd in all brands of lipsticks and eye pencils studied were $41.86 \mu \mathrm{g} / \mathrm{g}$ and $53.42 \mu \mathrm{g} / \mathrm{g}$, respectively. This result showed that the concentrations of $\mathrm{Pb}$ were higher than $\mathrm{Cd}$ levels found in lipsticks samples. While for eye pencil, $\mathrm{Cd}$ concentrations were higher than $\mathrm{Pb}$ levels (Table 2).

The results obtained in terms of producer country are consistent with the results reported by Gunduz and Akman (30), which demonstrated high levels of $\mathrm{Pb}$ in Chinese and Taiwanese cosmetics and low levels in the cosmetics produced by the USA and France (25). The findings of this study on Cd content in eye pencil according to the producer country are consistent with the results of studies by Al-Saleh et al and Gondal et al, according which the high levels of $\mathrm{Cd}$ and $\mathrm{Pb}$ in cheap products are related to Chinese and Indian companies $(15,31)$.

The results demonstrated that the highest concentration of $\mathrm{Pb}$ was found in red color lipstick and the lowest one was observed in pink lipsticks. This finding can be attributed to the presence of impurity in the dye used for the production of these cosmetic products. The statistical analysis also revealed that the highest Cd concentration was found in red color lipstick made in China, while the lowest one was observed in lipstick made in France in all colors studied. Moreover, pink color lipsticks made in Turkey showed very low concentrations of $\mathrm{Cd}$. These differences may be attributed to the quality of raw materials used in these cosmetic products. The primary ingredients found in lipstick are oil, alcohol, and dye. $\mathrm{Pb}$ might be actual as impurities in the color additives (15). Therefore, high concentrations of $\mathrm{Pb}$ in lipstick are due to adding dyes, such as pink, brown, and red dyes to
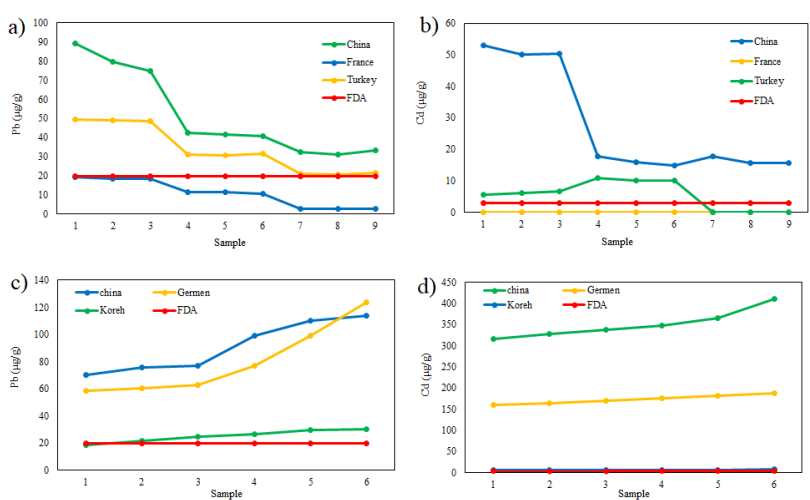

Figure 3. (a) Comparison of the mean $\mathrm{Pb}$ level in lipsticks with the FDA limit, (b) Comparison of the mean Cd level in lipsticks with the FDA limit, (c) Comparison of the mean $\mathrm{Pb}$ level in eye pencil with the FDA limit, and d) Comparison of the mean $\mathrm{Cd}$ level in eye pencil with the FDA limit.

these products. The most commonly used Cd compound in cosmetic products are $\mathrm{Cd}$ sulfide and $\mathrm{Cd}$ selenide for making different colors, such as yellow, orange, and black. Similarly, Nourmoradi et al also reported that the levels of $\mathrm{Pb}$ and $\mathrm{Cd}$ in dark colors were higher than those in light colors (32). Six replicates of reagent blanks fortified with low level standards were analyzed for each element. The LOD, calculated as three times of the standard deviations, and LOQ, calculated as 10 times of the standard deviations, are shown in Table 3. Comparing with the FDA guidelines, as can be seen in Table 4, similar results demonstrated that the lowest level of $\mathrm{Pb}$ was found in cosmetic products produced in France and the highest one was found in cosmetic products produced in China and Taiwan (30). Therefore, in order to prevent the adverse and harmful health effects of the cosmetic products on human, and to increase the community awareness on hidden dangers of cosmetics to promote health, the preparation and use of these products must be done according to the FDA standards.

\section{Conclusion}

In this study, 60 samples of lipstick and eye pencil of different brands were selected and analyzed by the ICPOES. Mean concentrations of $\mathrm{Pb}$ and $\mathrm{Cd}$ in all the brands studied were 41.86 and $53.42 \mu \mathrm{g} / \mathrm{g}$, respectively. The concentrations of $\mathrm{Pb}$ were higher than $\mathrm{Cd}$ levels found in

Table 3. Limits of detection and quantitation in the analytical portion

\begin{tabular}{lcc}
\hline & Cadmium & Lead \\
\hline LOD & 00.4876 & 0.05486 \\
LOQ & 0.01057 & 0.13798 \\
\hline
\end{tabular}

Table 4. Levels of lead and chromium in lipstick according to the FDA

\begin{tabular}{rc}
\hline Element & FDA \\
\hline $\mathrm{Pb}(\mathrm{ppm})$ & 10 \\
$\mathrm{Cd}(\mathrm{ppm})$ & $3,6+$ \\
\hline
\end{tabular}


the lipstick samples. While $\mathrm{Cd}$ levels were higher than $\mathrm{Pb}$ levels found in eye pencil samples. The results showed that in all lipstick samples, the metals concentration in lipsticks with pink color was lower than that of red color solid base lipsticks. The overall results showed that in all brands and colors of lipsticks, only $33 \%$ had $\mathrm{Pb}$ content less than the FDA limit, and among lipstick samples, $44 \%$ of all samples had Cd content less than the FDA limit of $3 \mu \mathrm{g} / \mathrm{g}$; however, in eye pencil samples, $100 \%$ of samples had Cd content above the recommended value of $3 \mu \mathrm{g} / \mathrm{g}$. Therefore, in order to prevent the adverse and harmful effects of the cosmetic products on human health, and to increase the community awareness on hidden dangers of cosmetics to promote health, the preparation and use of these products must be done according to the FDA standards.

\section{Acknowledgements}

The authors would like to thank Ahvaz Jundishapur University of Medical Sciences for financial support of this research. The research project was financially supported by the Student Research Committee of Ahvaz Jundishapur University of Medical Sciences (Grant No. 96S11).

\section{Ethical issues}

The authors declare that all data collected during the experiments are presented as expressed in the manuscript and no data from the study has been or will be published separately elsewhere.

\section{Competing interests}

The authors declare that they have no conflict of interests.

\section{Authors' contributions}

All authors have contributed in designing, collection, analysis, and interpretation of data. All authors have studied and approved the final manuscript.

\section{References}

1. Al-Dayel O, Hefne J, Al-Ajyan T. Human exposure to heavy metals from cosmetics. Orient J Chem 2011; 27(1): 1-11.

2. Khazaa SH, Al-Azawi KF, Eessa HA, Al-Gebori AM, Obayes HR, Khasraghi AH. Levels of lead and chromium ions in different brands of lipstick sold at local markets in Iraq. Eng Technol J 2018; 36(2 Part (B) Engineering): 147-51.

3. Asra R, Rusdi, Yandra RB, Nessa. Determination of heavy metal contaminations of lead and cadmium in selected lipstick products sold in Padang city using atomic absorption spectrophotometry. Indonesian Journal of Pharmaceutical and Clinical Research 2019; 2(1): 13-8. doi: 10.32734/idjpcr.v2i1.743.

4. Sani A, Gaya MB, Abubakar FA. Determination of some heavy metals in selected cosmetic products sold in Kano metropolis, Nigeria. Toxicol Rep 2016; 3: 866-9. doi: 10.1016/j.toxrep.2016.11.001.

5. Smith DR, Flegal AR. Lead in the biosphere: recent trends. Ambio 1995; 24(1): 21-3.

6. Samali A, Lawal HZ, Gevevieve O. Assessment of level of toxic heavy metal (PB) in local and foreign brands of lipsticks in FCT, Abuja, Nigeria. Bayero Journal of Pure and Applied Sciences 2017; 10(1): 318-22. doi: 10.4314/bajopas. v10i1.63S.

7. Malakootian M, Pourshaaban Mazandarany M, Eskandari M, Pourmahyabady R. Determination of lead concentration in solid and liquid lipsticks available in Iran-Kerman. Hormozgan Medical Journal 2012; 16(3): 241-6. [In Persian].

8. Soares AR, Nascentes CC. Development of a simple method for the determination of lead in lipstick using alkaline solubilization and graphite furnace atomic absorption spectrometry. Talanta 2013; 105: 272-7. doi: 10.1016/j. talanta.2012.09.021.

9. Naalbandi H, Saeedi M, Moharrami Moghanlou O, Akbari J, Morteza-Semnani K, Alizadeh R, et al. Evaluation of heavy metal content of some lipsticks in Iran market. Pharmaceutical and Biomedical Research 2016; 2(3): 31-7. doi: 10.18869/acadpub.pbr.2.3.31. [In Persian].

10. Malakootian M, Pourshaban Mazandarany M, Hossaini H. Lead levels in powders of surma (Kohl) used in Kerman. Journal of Kerman University of Medical Sciences 2010; 17(2): 167-74. [In Persian].

11. Umar MA, Caleb H. Analysis of metals in some cosmetics products in FCT-Abuja, Nigeria. Int J Res Cosmet Sci 2013; 3(2): 14-8.

12. Theresa OC, Onebunne OC, Dorcas WA, Ajani OI. Potentially toxic metals exposure from body creams sold in Lagos, Nigeria. Researcher 2011; 3(1): 30-7.

13. Alissa EM, Ferns GA. Heavy metal poisoning and cardiovascular disease. J Toxicol 2011; 2011: 870125. doi: $10.1155 / 2011 / 870125$.

14. Duruibe JO, Ogwuegbu MO, Egwurugwu JN. Heavy metal pollution and human biotoxic effects. Int J Phys Sci 2007; 2(5): 112-8.

15. Al-Saleh I, Al-Enazi S, Shinwari N. Assessment of lead in cosmetic products. Regul Toxicol Pharmacol 2009; 54(2): 105-13. doi: 10.1016/j.yrtph.2009.02.005.

16. Valet B, Mayor M, Fitoussi F, Capellier R, Dormoy $\mathrm{M}$, Ginestar J. Colouring agents in cosmetic products (excluding hair dyes). [cited 2018 Oct 11]; Available from: https://kundoc.com/pdf-colouring-agents-in-cosmeticproducts-excluding-hair-dyes-.html.

17. Volpe MG, Nazzaro M, Coppola R, Rapuano F, Aquino RP. Determination and assessments of selected heavy metals in eye shadow cosmetics from China, Italy, and USA. Microchem J 2012; 101: 65-9. doi: 10.1016/j. microc.2011.10.008.

18. Barros AI, Silva TV, Ferreira EC, Gomes Neto JA. Determination of lead in eye shadow and blush by highresolution continuum source graphite furnace atomic absorption spectrometry employing direct solid sampling. J Braz Chem Soc 2015; 26(1): 140-6. doi: 10.5935/01035053.20140228 .

19. Wang CC, Masi AN, Fernández L. On-line micellarenhanced spectrofluorimetric determination of rhodamine dye in cosmetics. Talanta 2008; 75(1): 135-40. doi: 10.1016/j. talanta.2007.10.041.

20. Campaign for Safe Cosmetics. A poison kiss: The problem of lead in lipstick. [cited 2019 Oct 4]; Available from: https://d124kohvtzl951.cloudfront.net/wp-content/ 
uploads/2017/03/02025212/Report_A-Poison-Kiss_ October_2007.pdf.

21. Nnorom IC, Igwe JC, Oji-Nnorom CG. Trace metal contents of facial (make-up) cosmetics commonly used in Nigeria. Afr J Biotechnol 2005; 4(10): 1133-8.

22. Samiee F, Leili M, Faradmal J, Torkshavand Z, Asadi G. Exposure to arsenic through breast milk from mothers exposed to high levels of arsenic in drinking water: Infant risk assessment. Food Control 2019; 106: 106669. doi: 10.1016/j.foodcont.2019.05.034.

23. Samiee F, Vahidinia A, Taravati Javad M, Leili M. Exposure to heavy metals released to the environment through breastfeeding: a probabilistic risk estimation. Sci Total Environ 2019; 650(Pt 2): 3075-83. doi: 10.1016/j. scitotenv.2018.10.059.

24. Vahidinia A, Samiee F, Faradmal J, Rahmani A, Taravati Javad M, Leili M. Mercury, lead, cadmium, and barium levels in human breast milk and factors affecting their concentrations in Hamadan, Iran. Biol Trace Elem Res 2019; 187(1): 32-40. doi: 10.1007/s12011-018-1355-5.

25. Vahid Dastjerdi M, Foroughi M, Mohammadi Moghadam F, Hassanzadeh A, Nourmoradi H. Studying the lead concentration rate in the most popular eye shadow cosmetcis in Isfahan city, Iran. Health System Research 2012; 8(3): 487-92. [In Persian].

26. Sharafi K, Fatahi N, Yarmohammadi H, Moradi M, Dargahi A. Determination of Cadmium and Lead Concentrations in Cosmetics (Lipstick and Hair Color) in Kermanshah Markets. Journal of Health 2017; 8(2): 143-50. [In Persian].

27. Zafarzadeh A, Shahryari A, Taziki S, Ahmadi N, Mirkarimi
K, Charkazi A. Assessment of cadmium and lead concentrations in different types of cosmetics products consumed in Iran. Natl J Physiol Pharm Pharmacol 2018; 8(8): 1200-4. doi: 10.5455/njppp.2018.8.0411729042018.

28. Ullah H, Noreen S, Fozia, Rehman A, Waseem A, Zubair $S$, et al. Comparative study of heavy metals content in cosmetic products of different countries marketed in Khyber Pakhtunkhwa, Pakistan. Arab J Chem 2017; 10(1): 10-8. doi: 10.1016/j.arabjc.2013.09.021.

29. U.S. Food and Drug Administration (FDA). FDA's Testing of Cosmetics for Arsenic, Cadmium, Chromium, Cobalt, Lead, Mercury, and Nickel Content. [cited 2019 Oct 4]; Available from: https://www.fda.gov/cosmetics/potentialcontaminants-cosmetics/fdas-testing-cosmetics-arseniccadmium-chromium-cobalt-lead-mercury-and-nickelcontent.

30. Gunduz S, Akman S. Investigation of lead contents in lipsticks by solid sampling high resolution continuum source electrothermal atomic absorption spectrometry. Regul Toxicol Pharmacol 2013; 65(1): 34-7. doi: 10.1016/j. yrtph.2012.10.009.

31. Gondal MA, Seddigi ZS, Nasr MM, Gondal B. Spectroscopic detection of health hazardous contaminants in lipstick using Laser Induced Breakdown Spectroscopy. J Hazard Mater 2010; 175(1-3): 726-32. doi: 10.1016/j.jhazmat.2009.10.069.

32. Nourmoradi H, Foroghi M, Farhadkhani M, Vahid Dastjerdi M. Assessment of lead and cadmium levels in frequently used cosmetic products in Iran. J Environ Public Health 2013; 2013: 962727. doi: 10.1155/2013/962727. 